\title{
Luaran Penutupan Duktus Arteriosus Persisten Transkateter di Rumah Sakit Dr. Hasan Sadikin Bandung
}

\author{
Rahmat Budi Kuswiyanto, Armijn Firman, Putria Rayani, Sri Endah Rahayuningsih \\ Departemen Ilmu Kesehatan Anak, Fakultas Kedokteran Universitas Padjadjaran/ RSUP Hasan Sadikin, Bandung
}

\begin{abstract}
Saat ini penutupan duktus arteriosus persisten (DAP) transkateter merupakan terapi pilihan karena memiliki efikasi yang baik, masa rawat yang singkat, risiko yang lebih rendah, dan bebas dari parut dada. Tujuan penelitian ini adalah mengevaluasi luaran jangka pendek dan menengah penutupan DAP transkateter. Penelitian merupakan laporan deskriptif analitik pasien yang menjalani penutupan DAP transkateter secara konsekutif di RS Dr. Hasan Sadikin Bandung selama periode Mei 2011 sampai dengan Juni 2014 dengan melakukan evaluasi pemeriksaan klinis dan ekokardiografi saat 24 jam, 1, 3, 6, dan 12 bulan setelah prosedur. Selama periode penelitian terdapat 132 pasien DAP yang menjalani penutupan transkateter, terdiri atas 42 laki-laki dan 90 perempuan, dengan median usia 3,9 tahun, berat badan $11,25 \mathrm{~kg}$, tekanan sistol arteri pulmonalis $56 \mathrm{mmHg}$, ukuran defek 3,4 mm, flow ratio 2,8, fluoroscopy time 16 menit, dan procedure time 67 menit. Segera setelah prosedur 54\% memperlihatkan penutupan lengkap, smoky residual 41\%, dan residual ringan 6\%. Sebagian besar pasien dipulangkan sehari setelah prosedur, tidak ada yang meninggal dan komplikasi hanya 3,8\%. Semua pasien memperlihatkan penutupan lengkap pada follow-up. Penutupan DAP transkateter merupakan terapi yang aman dan efektif dengan masa rawat yang singkat dan komplikasi yang minimal. [MKB. 2016;48(4):234-40]
\end{abstract}

Kata kunci: Duktus arteriosus persisten, penutupan transkateter

\section{Outcome of Transcatheter Occlusion of Patent Ductus Arteriosus in Dr. Hasan Sadikin General Hospital Bandung: a Preliminary Report}

\begin{abstract}
Transcatheter closure of patent ductus arteriosus (PDA) is a treatment of choice with good efficacy, shorter hospitalization, less risks, and chest scar free. The objective of this study was to evaluate the immediate and midterm outcomes of transcatheter closure of PDA. An analytic descriptive study was peformed on patients underwent transcatheter PDA occlusion in Dr. Hasan Sadikin General Hospital Bandung between May 2011 and June 2014. Evaluation was conducted through clinical examination and echocardiography 24 hours, 1, 3, 6 and 12 months after the procedure. The procedure was successful in 132 PDA patients (42 males and 90 females). The median age, body weight, systolic pulmonary artery pressure, PDA size, flow ratio, fluoroscopy time, and procedure time were 3.9 years, $11.25 \mathrm{~kg}, 56 \mathrm{mmHg}, 3.4 \mathrm{~mm}, 2.8,16$ minutes, and 67 minutes, respectively. Immediately after the procedure, $54 \%$ patients had complete closure, $41 \%$ experienced smoky residual shunt and only $5 \%$ experienced small residual shunt. The mortality and complication rate was 3.8\%. Most of the patients were discharged the next day after the procedure. All patients showed complete closure during followed-up. Transcatheter closure of PDA is safe and effective with shorter hospitalization and minimum complications. [MKB. 2016;48(4):234-40]
\end{abstract}

Key words: Patent ductus arteriosus transcatheter closure

Korespondensi: Rahmat Budi Kuswiyanto,dr., SpA(K), M.Kes, Divisi Kardiologi Departemen Ilmu Kesehatan Anak Fakultas Kedokteran Universitas Padjadjaran/Rumah Sakit Dr. Hasan Sadikin Bandung, Jalan Pasteur No. 38 Bandung, mobile 08122023051,e-mai rahmat_budi_k@yahoo.co.id 


\section{Pendahuluan}

Penyakit jantung bawaan merupakan salah satu penyebab utama kematian bayi dan anak yang dipengaruhi oleh berbagai faktor seperti diagnosis yang terlambat, ketidaktahuan, dan tata laksana yang tidak tepat. ${ }^{1}$ Duktus arteriosus persisten (DAP) yang merupakan 1/8-1/10 dari seluruh penyakit jantung bawaan dengan insidensi sekitar 1 per 2.000-5.000 kelahiran hidup. ${ }^{2}$ Di Jawa Barat diperkirakan terdapat 1.000 kasus DAP per tahun. ${ }^{1}$ Duktus arteriosus persisten ialah penyakit jantung nonsianotik disebabkan oleh patensinya duktus arteriosus setelah bayi lahir yang menghubungkan arteri pulmonalis dengan aorta desenden. ${ }^{3}$

Standar emas penutupan duktus arteriosus persisten adalah koreksi secara pembedahan sejak tahun 1993, namun pada 3 dekade terakhir penutupan duktus arteriosus persisten secara transkateterisasi memberikan luaran yang cukup baik. Luaran jangka panjang pernah diteliti oleh Ardakani dkk. ${ }^{3}$ pada anak dan hasilnya menunjukkan bahwa luaran jangka panjangnya memberikan hasil yang baik. namun keterbatasan penelitiannya adalah tidak mencantumkan teknik penutupan DAP. Penelitian lain yang dilakukan Gupta dkk. ${ }^{4}$ menunjukkan luaran penutupan DAP secara transkateterisasai sangat efektif memperbaiki fungsi ventrikel kiri, namun keterbatasan penelitiannya adalah pada jumlah sampel yang sedikit. Keberhasilan penutupan DAP transkateter mempunyai keunggulan yang lebih banyak dibanding dengan pembedahan, antara lain tidak diperlukan torakotomi yang akan meninggalkan parut, masa perawatan yang lebih pendek, menurunkan kebutuhan akan ruang rawat intensif, hasil yang atraktif dan efektif, serta komplikasi yang sedikit. ${ }^{5-8}$ Tujuan penelitian adalah evaluasi luaran jangka pendek dan menengah penutupan DAP transkateter di Rumah Sakit Dr. Hasan Sadikin Bandung.

\section{Metode}

Penelitian merupakan deskriptif analitik pasien yang menjalani penutupan DAP transkateter secara konsekutif di RS Dr. Hasan Sadikin Bandung selama periode Mei 2011 sampai dengan Juni 2014, dengan melakukan evaluasi pemeriksaan klinis dan ekokardiografi pada saat 24 jam, 1, 3, 6 serta 12 bulan setelah prosedur. Subjek adalah penderita DAP yang menjalani penutupan transkateter secara konsekutif. Persetujuan diperoleh dari orangtua, wali, atau pasien sendiri bila sudah dewasa.

Prosedur penutupan DAP yang dipergunakan mengacu kepada $\mathrm{Alwi}^{2}$ dengan modifikasi sesuai dengan keadaan RS Dr. Hasan Sadikin Bandung. Prosedur dilakukan dengan anestesi umum tanpa intubasi, kecuali untuk pasien yang kooperatif dengan anestesi lokal. Akses mempergunakan vena dan arteri femoral dengan menggunakan sheath ukuran 4, 5, atau 6 French. Heparin 50 international unit/kg diberikan intra-arterial setelah akses didapatkan dan sefazolin $50 \mathrm{mg} /$ $\mathrm{kg}$ intravena. Sebelum penutupan dilakukan penilaian hemodinamik termasuk flow ratio dan resistensi vaskular paru. Aortogram dibuat dengan kateter pigtail setinggi defek, sebelah distal dari arkus aorta, dengan proyeksi lateral atau right anterior oblique untuk menilai ukuran dan morfologi DAP, mencakup diameter tersempit, ukuran maksimal ampula, panjang DAP, dan diameter aorta desenden. Morfologi DAP ditentukan berdasarkan klasifikasi menurut Krichenko dkk. ${ }^{9}$

Kateter multi purpose untuk mengukur tekanan arteri pulmonalis dan crossing dari arteri pulmonalis melalui DAP ke aorta desenden. Alat penutup adalah amplatzer ductal occlude, lifetech ductal occluder, PDA-R atau coil, bergantung pada bentuk defeknya. Pengukuran ulang tekanan di aorta dan arteri pulmonalis dilakukan sebelum alat penutup dilepaskan dari kabel. Bila posisi dan letak alat penutup baik maka dilakukan pelepasan alat penutup dari kabel. Aortogram ulang untuk menilai hasil penutupan.

Evaluasi segera dilakukan setelah penutupan berdasarkan perubahan sifat murmur dan juga aortogram ulang berupa: 1). penutupan lengkap bila tidak didapatkan pirau residual; 2). smoky residual bila terdapat pirau residual melalui alat penutup seperti asap mengepul tanpa jet; 3). residual kecil bila terdapat residual kurang dari $2 \mathrm{~mm}$ dengan pirau yang tidak bermakna; 4). pirau residual bermakna bila terdapat pirau residual lebih dari $2 \mathrm{~mm}$ di antara alat penutup dengan lumen DAP dan pada auskultasi masih terdengar murmur kontinu.

Evaluasi berdasarkan atas pemeriksaan ekokardiografi pada saat 24 jam, 1, 3, 6, 12 bulan pascaprosedur berupa: 1). penutupan lengkap bila tidak didapatkan pirau residual; 2). smoky residual bila didapatkan residual kecepatan rendah tanpa disertai jet; 3). pirau residual kecil bila terdapat residual kecil dengan pirau jet pada color-flow doppler dengan perbedaan tekanan yang tidak bermakna; 4). pirau residual bermakna bila terdapat residual dengan gradien tekanan lebih dari $40 \mathrm{mmHg}$ pada pemeriksaan 


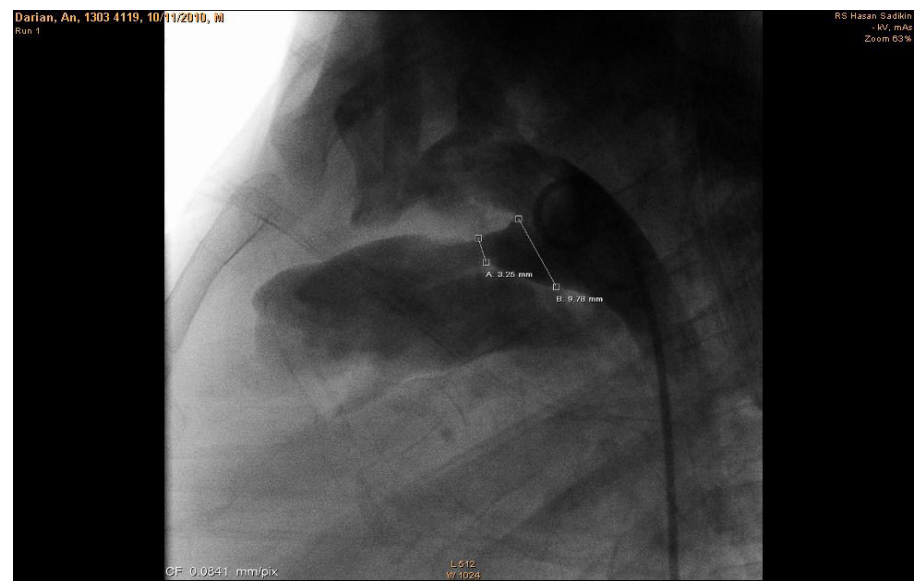

Gambar 1 Pengukuran Ukuran Tersempit dan Ampula DAP berdasarkan Angiogram

doppler dan terdengar murmur sistolik atau kontinu pada auskultasi.

Efikasi penutupan DAP transkateter dibagi atas: 1). keberhasilan prosedur akut adalah proporsi pasien yang berhasil dilaksanakan implantasi dari seluruh pasien yang menjalani prosedur; 2). efikasi akut adalah proporsi jumlah pasien yang memperlihatkan penutupan lengkap segera setelah implantasi dari seluruh pasien yang berhasil dipasang alat penutup; 3). efikasi sebelum pulang adalah proporsi pasien yang memperlihatkan penutupan lengkap 24 jam setelah prosedur sebelum penderita pulang; 4 ). keberhasilan menghilangnya murmur adalah menghilang murmur segera setelah penutupan dan pada saat pasien dipulangkan; dan 5). efikasi 3, 6, 12 bulan adalah proporsi pasien yang memperlihatkan penutupan lengkap pada follow-up 3, 6, dan 12 bulan dari seluruh pasien yang menjalani follow-up. Data dikumpulkan dan dicatat, kemudian diolah menggunakan software stastistik.

\section{Hasil}

Sejak bulan Mei 2011 sampai Juni 2014 terdapat 132 orang pasien yang menjalani penutupan DAP transkateter di RSHS, terdiri atas 42 lakilaki (32\%) dan 90 (68\%) perempuan (Tabel 1). Sebanyak 99 pasien (75\%) memperlihatkan gangguan pertumbuhan dengan status gizi kurang menurut standar WHO, 21\% di antaranya dengan status gizi buruk. Gagal jantung berat didapatkan pada 20 orang $(15 \%)$. Gagal jantung ringan pada 91 orang $(69 \%)$. Sembilan orang dengan sindrom Down dan 3 orang dengan sindrom rubela kongenital. Sebanyak 32 orang disertai dengan defek lain berupa coarctasio aorta ringan 5 orang, ASD sekundum kecil 3 orang, aortic
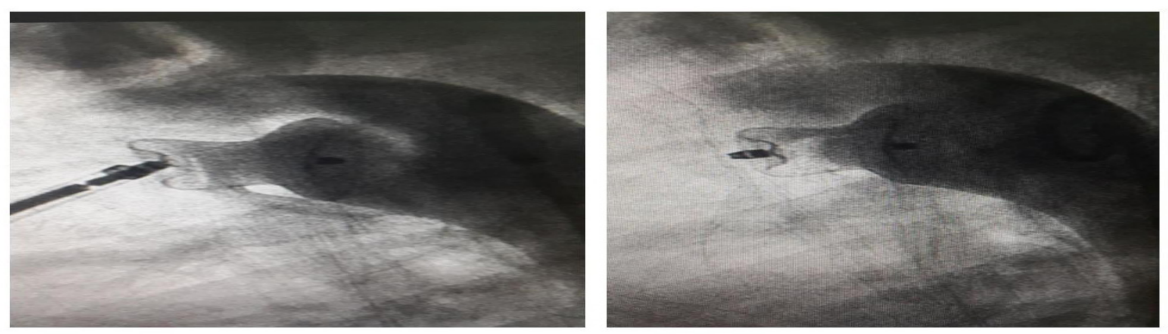

\section{Gambar 2 Aortogram Ulang Memperlihatkan Smoky Residual Setelah Alat Penutup Diletakkan di Dalam DAP Sebelum Dilepaskan dari Kabel (Kiri) dan Penutupan Lengkap Setelah Dilepaskan dari Kabel}


Tabel 1 Profil klinis pasien DAP di Rumah Sakit Dr. Hasan Sadikin Bandung

\begin{tabular}{lcc}
\hline & Median & Retang \\
\hline Usia (bulan/tahun) & 3,9 & 2,47 bulan-26 tahun \\
Berat badan (kg) & 11,25 & $3,7-60$ \\
PAP sistol (mmHg) & 56 & $15-114$ \\
PAP diastol (mmHg) & 24 & $10-64$ \\
Ukuran defek (mm) & 3.4 & $0,64-10.2$ \\
Flow rasio & 2.8 & $1,3-4,6$ \\
Fluro time (menit) & 16 & $11-45$ \\
Procedure time (menit) & 67 & $42-138$ \\
\hline
\end{tabular}

stenosis ringan 5 orang, dan regurgitasi mitral 4 orang. Hampir semua pasien memperlihatkan peningkatan tekanan arteri pulmonalis, kecuali pada pasien dengan ukuran DAP $1 \mathrm{~mm}$. Lima puluh tiga pasien (40\%) telah memperlihatkan tekanan paru melebihi $2 / 3$ tekanan sistemik. Berdasarkan klasifikasi menurut Krichenko, tipe DAP yang terbanyak adalah tipe A1 53\%, tipe A2 $24 \%$, tipe A3 7\%, tipe B 3\%, tipe C 9\%, tipe E 4\%, tetapi tidak didapatkan tipe D.

Alat penutup yang dipergunakan adalah amplatzer ductal occlude(ADO) I pada 75 pasien (57\%) dengan median ukuran alat penutup 8/6, ADO II 26 (20\%), PDA-R 22 pasien (17\%), lifetech ductal occluder 8 pasien, dan PFM coil seorang pasien. Penggantian alat penutup dilakukan pada 2 pasien karena pengukuran yang kurang tepat, tetapi tidak didapatkan kegagalan pemasangan.

Segera setelah implantasi sebanyak 72 (54\%) memperlihatkan hasil penutupan lengkap, 54 (41\%) smoky residual dan 6 (5\%) dengan residual ringan, tetapi tidak didapatkan pirau residual moderat atau besar yang bermakna. Hampir semua pasien tidak menunjukkan perbedaan tekanan yang bermakna aorta asenden dengan aorta descenden dan juga arteri pulmonalis kiri dengan arteri pulmonalis utama, kecuali pada pasien yang disertai dengan coarctasio aorta memperlihatkan penyempitan pada angiogram dengan perbedaan tekanan tertinggi $10 \mathrm{mmHg}$.

Pada auskultasi segera setelah implantasi hampir semua pasien menunjukkan perubahan sifat murmur, dari murmur kontinu menjadi menghilang, dan hanya sebagian kecil dengan sistolik murmur pada pemantauan selanjutnya.

Pada follow-up 24 jam pascaprosedur; 119 pasien $(90 \%)$ memperlihatkan penutupan lengkap, 6 orang masih memperlihatkan pirau residual, dua di antaranya dengan pirau residual bermakna. Kelompok yang memperlihatkan residual didapatkan pada pasien yang memakai PDA-R dan seorang dengan ADO II. Pada followup selanjutnya semua pasien memperlihatkan penutupan lengkap setelah satu tahun. Hanya seorang memperlihatkan penutupan lengkap setelah 2 tahun, yaitu pada anak dengan rubella kongenital. Tidak didapatkan perbedaan tekanan yang bermakna pada ekokardiogram di arteri pulmonalis kiri dengan aorta desenden.

Komplikasi yang didapatkan berupa demam transien pada seorang pasien membaik setelah pemberian heparin, penurunan hemoglobin sampai memerlukan transfusi pada seorang, gangguan irama jantung berupa SVT pada seorang dengan sindrom rubela kongenital yang kembali menjadi irama sinus setelah pemberian verapamil. Tidak ada pasien yang meninggal. Embolisasi pada dua pasien, tetapi berhasil diambil dengan snare dan dilakukan pemasangan ulang. Sebagian besar pasien dipulangkan keesokan hari setelah prosedur dengan median length of stays 3 hari. Sebanyak tujuh pasien

Tabel 2 Hasil Penutupan DAP Transkateter di Rumah Sakit Dr. Hasan Sadikin Bandung

\begin{tabular}{lcccccc}
\hline & Segera & 24 Jam & 1 Bulan & 3 Bulan & 6 Bulan & 12 Bulan \\
\hline Penutupan lengkap & $72(54 \%)$ & $117(89 \%)$ & $129(98 \%)$ & $129(98 \%)$ & $131(99 \%)$ & $131(99 \%)$ \\
Smoky residual & $54(41 \%)$ & $10(7 \%)$ & 0 & 0 & 0 & 0 \\
Residual kecil & $6(5 \%)$ & $5(4 \%)$ & $3(2 \%)$ & $3(2 \%)$ & $1(1 \%)$ & $1(1 \%)$ \\
Residual signifikan & 0 & 0 & 0 & 0 & 0 & 0 \\
\hline
\end{tabular}


Rahmat Budi: Luaran Penutupan Duktus Arteriosus Persisten Transkateter di Rumah Sakit Dr. Hasan Sadikin Bandung

Tabel 3 Efikasi Penutupan DAP Transkateter

\begin{tabular}{lcc}
\hline \multicolumn{1}{c}{ Principal Efficacy } & n & Persentase (\%) \\
\hline Keberhasilan prosedur akut & $130 / 132$ & 98 \\
Efikasi akut & $73 / 132$ & 54 \\
Efikasi 24 jam & $117 / 132$ & 89 \\
Murmur menghilang sebelum pulang & $122 / 132$ & 93 \\
Efikasi 1 bulan & $129 / 132$ & 99 \\
Efikasi 3 bulan & $129 / 132$ & 99 \\
Efikasi 6 bulan & $131 / 132$ & 99 \\
Efikasi 12 bulan & $131 / 132$ & 99 \\
\hline
\end{tabular}

dirawat lebih lama karena memerlukan transfusi, terapi heparin dan masalah administrasi.

Pada follow-up satu bulan sebagian besar memperlihatkan penutupan yang lengkap, hanya dua orang pasien masih memperlihatkan residual ringan. Pada pemantauan 3, 6, dan 12 bulan hampir semua pasien memperlihatkan penutupan yang lengkap, kecuali seorang pasien dengan sindrom rubela kongenital yang menutup lengkap setelah dua tahun. Tidak ditemukan perbedaan tekanan yang bermakna pada pengukuran Doppler antara arteri pulmonalis dan aorta.

\section{Pembahasan}

Bedah ligasi untuk menangani DAP merupakan tindakan yang sudah dianggap sebagai standar pengobatan yang efektif, namun invasif sehingga dikembangkan penutupan DAP transkateter atau tindakan intervensi nonbedah yang mempunyai efektivitas yang serupa, tetapi kurang invasif. Keunggulan lain intervensi nonbedah adalah lama rawat yang singkat dan tidak terdapat jaringan parut di dada. ${ }^{5 .}$

Penutupan DAP transkateter pertamakali diperkenalkan oleh Portsmann. ${ }^{5}$ Setelah itu, Raskind dkk. ${ }^{10}$ mengembangkan alat yang dapat diterima secara luas dengan kejadian pirau residual mencapai $20 \%$ dan juga risiko stenosis di arteri pulmonal kiri yang tinggi. Sejak saat itu banyak penelitian dikembangkan dengan berbagai macam teknik dan alat penutup untuk menutup DAP dengan hasil yang bervariasi.

Walaupun efikasi akut penutupan DAP di RSHS hanya 54\%, tetapi pada evaluasi 24 jam pascaprosedur efikasinya meningkat menjadi $89 \%$, bahkan sampai $99 \%$ pada follow-up tiga bulan sampai satu tahun. Dua orang pasien masih memperlihatkan residual shunt pada followup satu tahun. Hal ini menggambarkan proses trombosis memerlukan waktu paling sedikit 24 jam pascapenutupan. Penutupan lengkap terjadi lebih lambat terutama pada pasien dengan PDA besar, sindrom rubela kongenital, dan pasien yang menggunakan PDA-R yang memang didisain untuk para penderita dengan tekanan tinggi arteri pulmonal. Pada sindrom down dan sindrom rubela kongenital sering

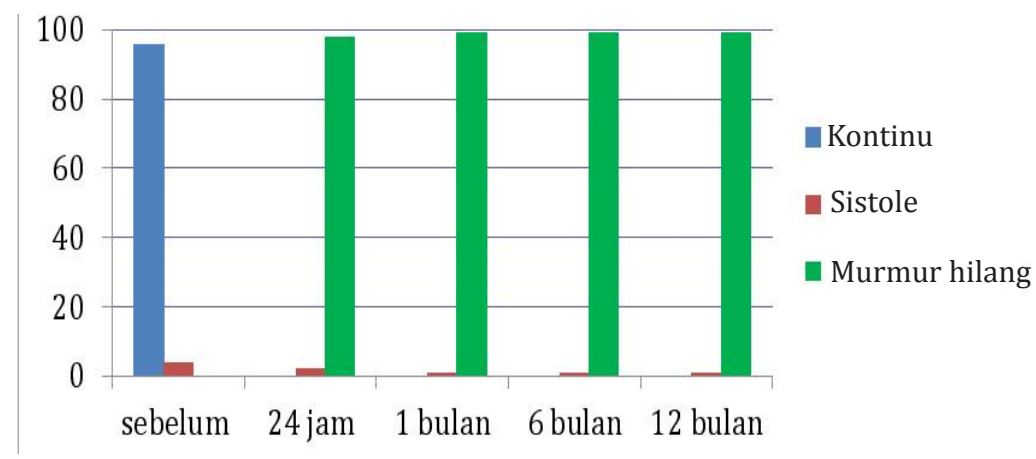

Gambar 3 Perubahan Sifat Murmur Sebelum dan Sesudah Penutupan DAP 
disertai kelainan penyerta di organ lain yang mungkin memengaruhi hasil penutupan. Setelah penutupan DAP berat badan pasien naik secara bermakna pada pemantauan selanjutnya, kecuali pada penderita sindrom down dan sindrom rubela kongenital.

Perubahan karakteristik bunyi jantung tambahan dari murmur kontinu menjadi tidak terdengar hampir mencapai $98 \%$ dan hanya sebagian kecil yang masih terdengar murmur sistole. Auskultasi bunyi jantung tambahan dapat dijadikan acuan untuk menilai efektivitas penutupan. Peningkatan pada tekanan vaskular paru didapatkan pada sebagian besar pasien dengan median tekanan $55 \mathrm{mmHg}$. Keadaan ini memperlihatkan bahwa DAP menyebabkan peningkatan tekanan paru yang cukup potensial, walaupun beberapa pasien langsung mengalami penurunan tekanan paru segera setelah ditutup. Beberapa pasien tekanan paru tidak segera turun segera setelah penutupan, terutama pada pasien dengan tekanan melebihi $2 / 3$ sitemik. Hal ini mungkin disebabkan oleh peningkatan tekanan yang terjadi sudah menyebabkan perubahan resistensi vaskular paru yang menetap, tetapi tidak sampai menyebabkan hipertensi pulmonal krisis.

Berbeda halnya dengan laporan lain, tidak didapatkan obstruksi arteri pulmonalis dan aorta tidak didapatkan pada laporan ini. Beberapa pasien dengan berat kurang dari $6 \mathrm{~kg}$ dan pasien dengan coarctasio aorta masih dapat dilakukan penutupan tanpa stenosis yang berarti di aorta atau arteri pulmonalis. Pada penelitian yang dilakukan Dimas dkk. ${ }^{11}$ kegagalan penutupan DAP pada berat badan kurang dari $6 \mathrm{~kg}$ dapat terjadi disebabkan ketidaksesuaian alat penutup, namun penutupan DAP pada anak berat badan di bawah $6 \mathrm{~kg}$ masih boleh dipertimbangkan. Prosedur lebih lama lebih sering didapatkan pada bayi dengan berat di bawah $5 \mathrm{~kg}$ sehingga sampai saat ini penutupan DAP pada bayi, terutama bayi prematur masih merupakan tantangan tersendiri. Beberapa alat penutup dilaporkan dapat untuk menutup DAP pada bayi prematur, tetapi belum tersedia di Indonesia. ${ }^{12-15}$

Gejala gagal jantung merupakan salah satu komplikasi. Penelitian ini telah memperlihatkan perbaikan klinis dan fungsi, sedangkan dimensi ventrikel kiri mengalami perbaikan setelah 6 bulan pascapenutupan DAP. ${ }^{16-19}$

Komplikasi yang terjadi yaitu, sebesar 3,8\%, lebih rendah dibanding dengan laporan lain ${ }^{20}$ Komplikasi yang serius didapatkan pada seorang pasien dengan SVT yang pada akhirnya berhasil ditutup defeknya memakai approach retrograde dari aorta. Komplikasi yang lainnya berupa komplikasi minor, yaitu berupa demam dan juga trombosis.

Penutupan DAP transkateter memerlukan masa rawat yang singkat dan hampir sebagian besar pasien akan kembali ke ruang rawat biasa pascatindakan sehingga keadaan ini memberikan keuntungan tersendiri untuk Rumah Sakit Dr. Hasan Sadikin Bandung (RSHS) yang memiliki keterbatasan ruang rawat inap intensif dan intermediet, khususnya untuk anak.

Simpulan, laporan ini memberikan gambaran bahwa penutupan DAP transkateter adalah aman dan efektif pada pemantauan jangka pendek dan menengah, serta dapat dijadikan pilihan untuk sarana dengan keterbatasan ruang intensif. Follow-up jangka panjang lebih lanjut masih diperlukan untuk menilai keamanan prosedur ini.

\section{Daftar Pustaka}

1. BKKBN. Profil Kependudukan dan Pembangunan di Indonesia Tahun 2013. Jakarta: BKKBN; 2013.

2. Alwi M. Patent ductus arteriosus occlusion with the amplatzer device. Dalam: Sievert $\mathrm{H}$, Qureshi SA, Wilson N, Hijazi ZM, penyunting. Percutaneous interventions for congenital heart disease. Edisi ke-1. Boca Raton: CRC Press; 2007. hlm. 377-84.

3. Ardakani MB, Ardakani MAB, Hosseini SH, Noori N. Long-term results of transcathether closure of patent ductus arteriosus in infants using amplatzer duct occluder. Iran J Pediatr. 2013;23(4):411-6.

4. Gupta SK, Krishnamoorthy KM, Jaganmohan AT, Sivasankaran S, Sanjay G, Bijulal S, dkk. Percutaneous closure of patent ductus arteriosus in children:Immediate and shortterm changes in left ventricular systolic and diastolic function. Ann Pediatr Cardiol. 2011;4(2):139-44.

5. Choi DY, Kim NY, Kim SH. The results of transcathether occlusion of patent ductus arteriousus: success rate and complications over 12 years in single centre. Korean Circ J. 2010;40(5):230-4.

6. Masura J, Tittel P, Gavora P, Padnar T. Long-term outcome of transcatherther patent ductus arteriosus closure using Amplatzer duct occluders. Am Heart J. 2006;151(3):755e7-10.

7. Thanopoulos B, eleftheratos N, Tzamos K, Stefanadis C. Transcatherther closure of 
patent ductus arteriosus using the new Amplatzer duct occlude. Am Heart J. 2008; 156(5):917e1-6.

8. Parra BR, Cruss RA, Rebolledo PV, Robles CJ, Chaves FA, Beirana PL. Transcathether closure of patent ductus arteriosus using the amplatzer duct occlude in nfant under 1 year of age. Rev Esp Cardiol. 2009;62(8):867-74.

9. Krichenko A, Benson LN, Burrows P, Moes CHF, Mc Lauglin P, Freedom RM. Angiographic classification of the isolated, persistently patent ductus arteriosus and implications for percutaneous catheter occlusion. Am J Cardiol. 1989;63(12):877-80.

10. Raskind WJ, Mullins CE, Hellenbrand WE, Tait MA. Nonsurgical closure of patent ductus arteriosus: clinical application of the Raskind DAP occluder system. Circulation. 1987;75(3):583-92.

11. Dimas VV, Takao C, Ing FF, Mattamal R, Nugent AW, Grifka RG. Outcomes of transcatherther occlusion of patent ductus arteriosus in infant weighing $\leq 6 \mathrm{~kg}$. J Am Coll Cardiol Intv. 2010;3(12):1295-9.

12. Hamrick SEG, Hansman G. Patent ductus arteriosus of the preterm infant. Pediatrics. 2010;12(5):1020-30.

13. Mandhari P, Brown S, Kukkady A, Sammarakkody U. Surgical closure of patent ductus arteriosus in preterm low birth weight infants. Congenital Heart Disease. 2009;4(2):34-7.

14. Bass JL, Wilson N. Transcathether occlusion of the patet ducrus arteriosus in infants:experimental testing of a new Amplatzer device. Cathetherization Cardiovasc Intervent. 2013;83(2):250-5.

15. Prsa M, Ewert P. Transcathether of a patent ductus arteriosus in a preterm infant with an Ampaltzer vascular plug IV device. Cathetherization Cardiovascular Intervent. 2010;77(1):108-11.

16. Park Ya, Kim NK, Park SJ, Yun BS, Choi JY, Sul JH. Clinical outcome of transcathether closure of patent ductus arteriosus in small children weighing $10 \mathrm{~kg}$ or less. Korean J Pediatr. 2010;53(12):1012-7.

17. Ali SH, Abdalla SES. Percutaneous transcathether closure of patent ductus arteriosus:initial experience of Sohag University. Egyptian Heart J. 2014;66(2): 143-7.

18. Eerola A, Jokinen E, Boldt T, Pinkala J. The influence of percutaneous closure of PDA on left ventricular size and function. J Am Coll Cardiol. 2006;47(5):1060-6.

19. Azhar AS, El-Azim AAA, Habid HS. Transcatheter closure of patent ductus arteriosus:evaluating the effect of the learning curve of the outcome. Ann Pediatr Cardiol. 2009;2(1):36-40.

20. Gi JY, Chang SS, Joo WI, Ja YL, Soo JK. Complication after transcathether closure of patent ductus arteriosus. J Korean Med Sci. 2007;22(3):484-90. 